\title{
Seismic imaging and velocity structure around the JFAST drill site in the Japan Trench: low Vp, high $V p / V s$ in the transparent frontal prism
}

\author{
Yasuyuki Nakamura ${ }^{1,2^{*}}$, Shuichi Kodaira ${ }^{1,2}$, Becky J Cook ${ }^{3}$, Tamara Jeppson ${ }^{4}$, Takafumi Kasaya ${ }^{5,6}$, Yojiro Yamamoto ${ }^{1,2}$,
} Yoshitaka Hashimoto ${ }^{7}$, Mika Yamaguchi ${ }^{7,8}$, Koichiro Obana $^{1,2}$ and Gou Fujie ${ }^{1,2}$

\begin{abstract}
Seismic image and velocity models were obtained from a newly conducted seismic survey around the Integrated Ocean Drilling Program (IODP) Japan Trench Fast Drilling Project (JFAST) drill site in the Japan Trench. Pre-stack depth migration (PSDM) analysis was applied to the multichannel seismic reflection data to produce an accurate depth seismic profile together with a P wave velocity model along a line that crosses the JFAST site location. The seismic profile images the subduction zone at a regional scale. The frontal prism where the drill site is located corresponds to a typically seismically transparent (or chaotic) zone with several landward-dipping semi-continuous reflections. The boundary between the Cretaceous backstop and the frontal prism is marked by a prominent landward-dipping reflection. The P wave velocity model derived from the PSDM analysis shows low velocity in the frontal prism and velocity reversal across the backstop interface. The PSDM velocity model around the drill site is similar to the P wave velocity model calculated from the ocean bottom seismograph (OBS) data and agrees with the $P$ wave velocities measured from the core experiments. The average $V p / V s$ in the hanging wall sediments around the drill site, as derived from OBS data, is significantly larger than that obtained from core sample measurements.
\end{abstract}

Keywords: Japan Trench; Seismic image; P and S wave velocities; JFAST

\section{Background}

The 2011 Tohoku earthquake occurred along the Japan Trench subduction zone east off the northern Honshu island, Japan. The earthquake rupture likely propagated along the plate boundary up to the trench axis. (e.g., Ide et al. 2011; Kodaira et al. 2012). Rapid response drilling by the Integrated Ocean Drilling Program (IODP) Expedition 343 (Japan Trench Fast Drilling Project (JFAST)) successfully drilled through the inferred plate boundary fault approximately $6 \mathrm{~km}$ landward of the trench axis. The expedition obtained logging data and core samples, and installed and recovered temperature sensors (Chester et al. 2012). The drilled plate boundary

\footnotetext{
* Correspondence: yasu@jamstec.go.jp

'Institute for Research on Earth Evolution (IFREE), Japan Agency for Marine-Earth Science and Technology (JAMSTEC), 3173-25 Showa-machi, Kanazawa-ku, Yokohama, Kanagawa 236-0001, Japan

${ }^{2}$ Research and Development Center for Earthquake and Tsunami (CEAT), Japan Agency for Marine-Earth Science and Technology (JAMSTEC), 3173-25 Showa-machi, Kanazawa-ku, Yokohama, Kanagawa 236-0001, Japan Full list of author information is available at the end of the article
}

fault is very thin $(<5 \mathrm{~m})$ and localized in a pelagic clay layer approximately $15 \mathrm{~m}$ above the basal chert layer (Chester et al. 2013). Borehole breakout orientations indicate the stress state of the hanging wall is in normal fault regime and a complete stress drop occurred during the earthquake (Lin et al. 2013). The temperature observatory recorded a residual co-seismic frictional heat anomaly at the plate boundary (Fulton et al. 2013) and estimated a low friction coefficient $(<0.1)$ that is consistent with values from high-speed friction experiments on the fault core sample (Ujiie et al. 2013). All of these results support the hypothesis that co-seismic slip extended to the very shallow portion of the plate boundary. However, it is still difficult to fully understand the in situ physical properties of the hanging wall of the plate boundary fault because of the limited logging data (gamma ray and resistivity) and limited cored intervals obtained during the drilling expedition. Local scale seismic images were previously 
obtained in a high-resolution seismic survey around the drill site (Chester et al. 2012, Nakamura et al. 2013), but a regional scale seismic section crossing the drill site had not been obtained. A regional scale seismic data is necessary to determine the velocity structure of the wedge and directly connect the drill site information to the background regional scale geological structure. To understand the structure and the physical properties of hanging wall sediments, a post-drilling multi-channel seismic (MCS) survey was conducted around the JFAST drill site. We processed the MCS data up to the pre-stack depth migration (PSDM) to produce an accurate depth seismic image and the $\mathrm{P}$ wave velocity structure. We also modeled travel-times of converted $\mathrm{S}$ wave arrivals observed at the ocean bottom seismographs (OBSs) to obtain the shear-wave velocity information around the drill site, which cannot be retrieved using the MCS data. We compare the seismic-derived velocity information with drilling results and controlled pressure $V \mathrm{p}$ and $V$ s core measurements and discuss the similarities and differences between them.

\section{Methods}

\section{Seismic survey KR13-01}

The seismic survey cruise (KR13-01) was conducted in the Japan Trench region using R/V Kairei operated by Japan Agency for Marine-Earth Science and Technology (JAMSTEC) in January 2013. A tuned air gun array with 7,800 in. $^{3}$ of total volume was fired every $50 \mathrm{~m}$ along the survey lines. A 444 channel streamer cable (approximately $6 \mathrm{~km}$ maximum offset) was towed to record the seismic signals with a sampling interval of $2 \mathrm{~ms}$. The depth of the gun array and the streamer cable was 10 and $12 \mathrm{~m}$, respectively. In this study, we use the data obtained along two seismic lines, JFD1 and JFS12, as shown in Figure 1.

An OBS, developed for an operation deeper than 6,000 m, was deployed around site C0019 (Figure 1) to record the air gun signals with a sampling interval of 4 ms. The OBS JF1 was located at the lower most part of the Japan Trench landward slope, approximately $1 \mathrm{~km}$ north of the IODP site C0019 (Figure 1b). The OBS JF1 was not recovered by a normal self-popup recovery procedure, but it was recovered by the ROV KAIKO 7000II in April 2013 during the KR13-08 cruise.

\section{MCS data processing}

The MCS data were first processed following a conventional procedure that includes minimum phase conversion, predictive deconvolution, common midpoint (CMP) sorting, velocity analysis, normal moveout, stacking, and post-stack time migration (PoSTM). Noise reduction by $\mathrm{f}$-x projection (Soubaras 1995) and $\mathrm{f}$-x prediction filtering (Canales 1984) was applied to reduce the swell noise and seismic waves by local earthquakes. Surfacerelated multiple elimination and parabolic radon transform were applied to suppress multiples. Pre-stack time migration (PSTM) analysis was applied to produce a fine-tuned time-domain seismic image. This PSTM section was used to establish the structural formation model for further PSDM analysis.

The MCS data of the line JFD1 were processed until PSDM to produce the depth seismic section and the corresponding P wave velocity model. A 'layer-cake' approach was used for PSDM velocity analysis where we first determined the velocity in the shallowest formation and then sequentially moved down to deeper formations. The velocity model $v(z)$ in each formation has the following form: $v(z)$ $=v_{0}+g\left(z-z_{0}\right)$, where $z$ is the depth, $v_{0}$ is the $\mathrm{P}$ wave velocity at the top of the formation, $z_{0}$ is the top depth of the formation, and $g$ is the velocity gradient. A depth section was created by PSDM with a defined layer-cake velocity model, and horizon semblance was examined to evaluate the velocity model. We determined $v_{0}$ and $g$ to achieve the best improved horizon semblance over the target horizon by trial and error. Once a satisfactory layer-cake model was achieved, the velocity model was updated by a horizonbased residual velocity analysis which evaluates the moveout of migrated common reflection point (CRP) gathers using horizon semblance. The velocity was modified to shift the semblance peak to zero residual. The velocity model was finally updated by grid-based travel-time tomography to accommodate the local scale velocity variation. Clear but local reflective events (inter-layer segments) were picked for the input to the tomography, and grid-based velocity model was updated to flatten the CRP gathers at picked events. The velocity model cannot be resolved below the top of the oceanic crust due to the length of the streamer cable, so we use the deeper velocities determined in previous studies of the Japan Trench (Tsuru et al. 2000, Tsuru et al. 2002, Miura et al. 2005). Automatic gain control was used to enhance the deeper reflections in the gathers because we prioritized obtaining the best depth image and corresponding velocity model over amplitude preservation in this study.

\section{OBS data analysis}

The OBS recorded the seismic signal at longer offsets, and it is equipped with three component sensors (two horizontal and one vertical). As the number of the OBS used in this study was limited, the typical tomographic approach cannot be applied to the OBS data. Instead, we first applied the conventional tau-p/tau-sum method (Diebold and Stoffa, 1981, Shinohara et al. 1994) to obtain a 1D Vp model. The envelope of the vertical component waveforms was used for the tau-p/tau-sum analysis to enhance the signal in the tau-p domain. Horizontal components of the OBS data record the shear wave arrivals which were 

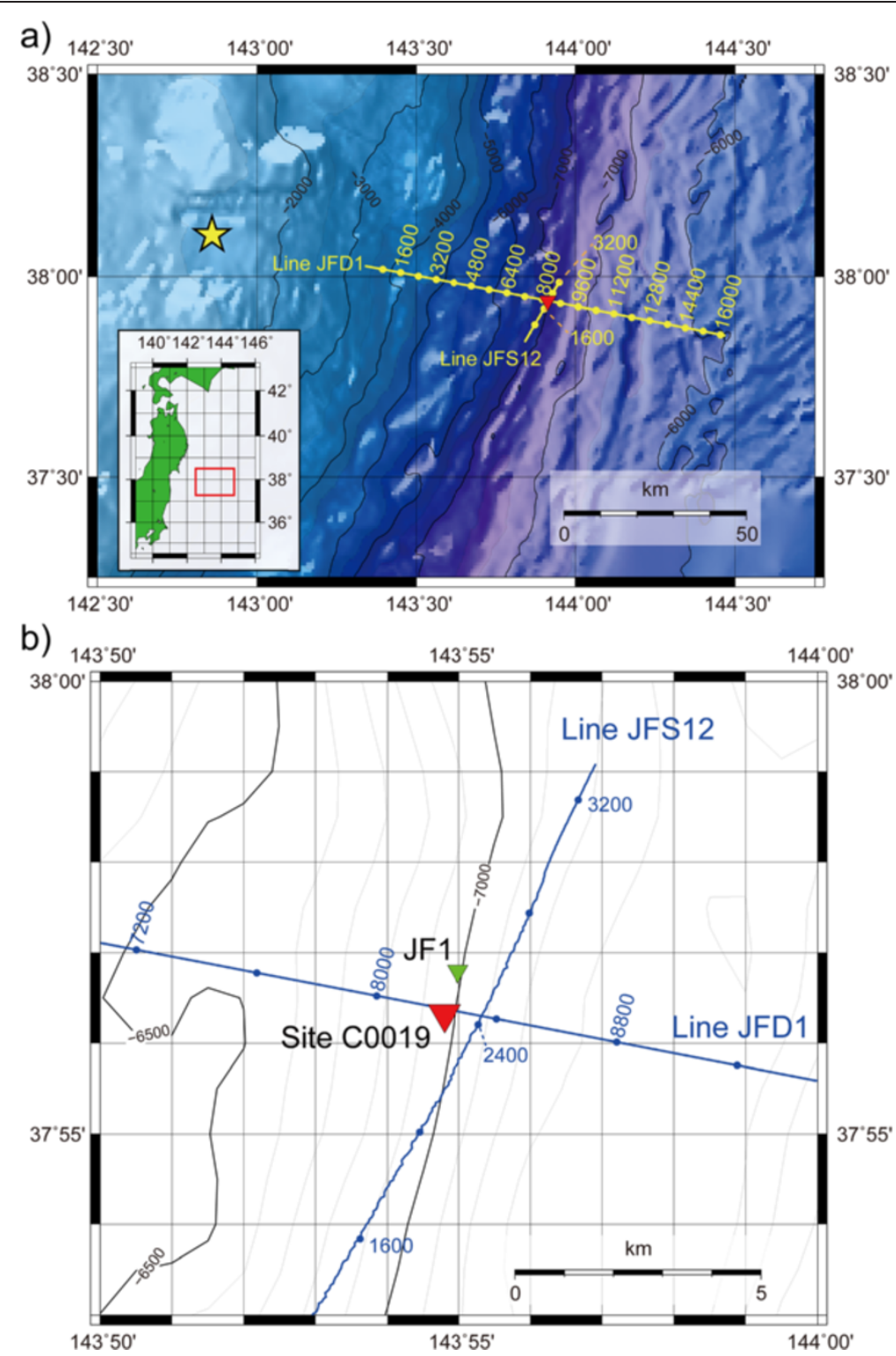

Figure 1 The location map with seismic lines. (a) Regional scale bathymetry map of the Japan Trench region, off Miyagi, northeastern Japan. Red rectangle in the inset map corresponds to the area shown in Figure 1a. Yellow star denotes the epicenter of the Tohoku earthquake that occurred on 11 March 2011. Yellow lines indicate the seismic survey lines used in this study. Yellow numbers are the CDP numbers. Red inverted triangle is the location of the JFAST drill site C0019. (b) Close-up map around drill site C0019 with bathymetry contours. Green inverted triangle indicates the site location of OBS JF1. Blue lines show the seismic survey lines and blue numbers are the CDP numbers.

originally emitted as $\mathrm{P}$ waves from the sounding source then converted to $\mathrm{S}$ waves before arriving at the OBS. In this study, we use the PPS-converted wave which was converted from $\mathrm{P}$ to $\mathrm{S}$ below the OBS location to estimate the average $V \mathrm{p} / V \mathrm{~s}$ in the layer/s between the seafloor and the conversion point (see Figure 2). The average $V \mathrm{p} / V \mathrm{~s}$ is calculated from following equation:

$$
V \mathrm{p} / V \mathrm{~s}^{\sim}\left(2 d \mathrm{t}+t_{\mathrm{c}}-t_{\mathrm{sf}}\right) /\left(t_{\mathrm{c}}-t_{\mathrm{sf}}\right)
$$

where $d \mathrm{t}$ is the time lag between refracted $\mathrm{P}$ wave and the converted PPS wave, and $t_{\mathrm{c}}$ and $t_{\mathrm{sf}}$ are the two-way travel time of the conversion point and the seafloor shown on the time-domain seismic section.

\section{P and S wave velocity measurements of the JFAST core sample}

We measured the $\mathrm{P}$ wave and $\mathrm{S}$ wave velocities of sediment core samples obtained from the frontal prism during the JFAST drilling expedition. Six samples, retrieved 
between 690.4 and 818.5 mbsf (Table 1), were measured under controlled pore fluid pressure using laboratory instruments at Kochi University and the University of Wisconsin-Madison. The lithology of these cores was mudstone (Expedition 343/343T Scientists, 2013). The design of the experiment is similar to that employed in the previous studies on saturated marine sediments (e.g., Tobin et al. 1994, Hashimoto et al. 2010). The pore pressure was kept at $500 \mathrm{kPa}$ for Core343-C0019E-7R (7R), and confining (effective) pressure was stepwise elevated from 1,000 to $18,000 \mathrm{kPa}$ during the measurements. For other cores, velocity measurements were carried out while pressurizing and depressurizing. The pore pressure was kept at $1,000 \mathrm{kPa}$, and effective pressure was stepwise changed from 1,000 to $68,000 \mathrm{kPa}$ and 68,000 to $500 \mathrm{kPa}$ during the measurements. In this study, we used the velocities measured while pressurizing. For the measurements, the sample was formed into a cylindrical shape, approximately $3.8 \mathrm{~cm}$ for $7 \mathrm{R}$ and $2.45 \mathrm{~cm}$ for others in diameter, and $5.4 \mathrm{~cm}$ for $7 \mathrm{R}$ and 1 to $2 \mathrm{~cm}$ for other cores in length.

\section{Results}

\section{Line JFD1 PSDM section}

Pre-stack depth migrated section of the line JFD1 (Figure 3) clearly shows the characteristic structure of the Japan Trench subduction zone at the location of the JFAST drill site C0019. Seaward of the trench, pelagic and hemipelagic sediments with thickness of 300 to $500 \mathrm{~m}$ cover the oceanic basement reflections, and the Moho reflection is also imaged 5 to $6 \mathrm{~km}$ below the basement reflection. Both the sediments and the basement are offset by normal faults producing a horst and graben structure. In the vicinity of the trench axis, the structures imaged on the PSDM section are similar to those observed on high-resolution seismic profiles (Nakamura et al. 2013), e.g., imbricate structure in the trench axis graben (see also Figure 4). The drill site C0019 penetrates the wedge-shaped, seismically chaotic or transparent frontal prism imaged beneath the lowermost landward slope. The plate boundary at the drill

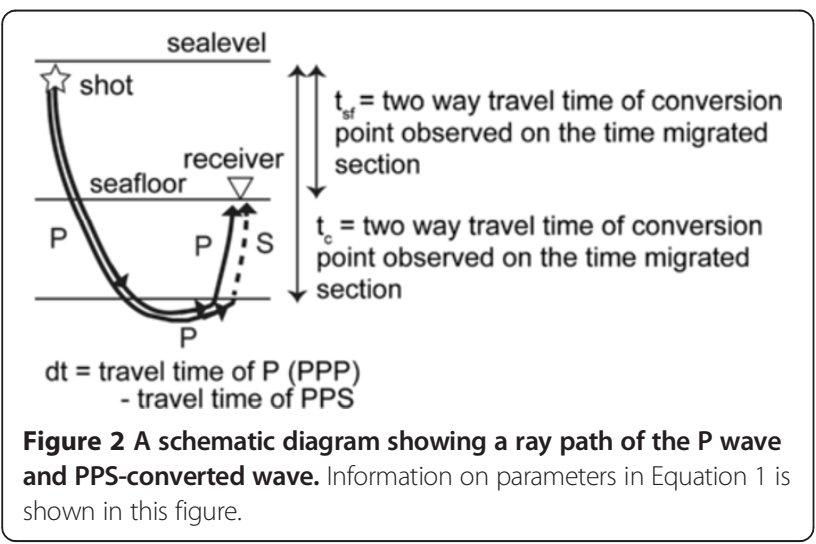

Table 1 List of the core samples used in this study

\begin{tabular}{llll}
\hline Sample & Depth (mbsf) & Lithologic unit & Measured at \\
\hline C0019E-4R & 690.4 & Unit 3 wedge sediments & UW \\
C0019E-6R & 704.3 & Unit 3 wedge sediments & UW \\
C0019E-7R & 713.2 & Unit 3 wedge sediments & Kochi \\
C0019E-8R & 720.8 & Unit 3 wedge sediments & UW \\
C0019E-15R & 817.5 & Unit 3 wedge sediments & UW \\
C0019E-16R & 818.5 & Unit 3 wedge sediments & UW \\
\hline
\end{tabular}

UW represents the University of Wisconsin-Madison.

site is located on a subducted horst block; the plate boundary reflection can be seen draping the horst at both seaward and landward edges. A few landward dipping weak reflections can be observed within the prism. These events are clearer than those on the high-resolution seismic profiles reported by Nakamura et al. (2013) because large volume air gun arrays and longer streamer cable were used to obtain the data for this study. Although these reflections are not really continuous and distinct, drilling results (e.g., Fulton et al. 2013, Ujiie et al. 2013) strongly suggest that Tohoku earthquake slip occurred along the plate boundary. The landward boundary of the frontal prism is a prominent landward dipping reflection corresponding to the backstop interface (Tsuru et al. 2000). The PSDM P wave velocity model (Figure 3c) shows a velocity inversion across the interface where backstop material overlies the frontal prism. The western part of the line JFD1, covering the upper to middle landward slope of the Japan Trench, shows a strong reflection 1,000 to $2,000 \mathrm{~m}$ below the seafloor which separates the slope sedimentary sequence from the deeper backstop unit, which was interpreted as Cretaceous sequences (e.g., von Huene and Culotta, 1989). Both the slope sediments and the underlying strong reflection are offset by normal faults (e.g., CDP 1300 to 1400). The vertical resolution of the seismic data can be estimated by the Rayleigh criterion of $L / 4$, where $L$ is the peak wavelength of the source at the local velocity of the medium, whereas the horizontal resolution is limited by the size of the first Fresnel zone; this is $\left(L^{*} d / 2\right)^{1 / 2}$, where $d$ is the depth of the target. The horizontal resolution might be collapsed to $L$ by the migration in the ideal case; however, it could be lower due to the noises and velocity errors used in the migration (e.g., Claerbout 1985, Stolt and Benson 1986, Yilmaz 2001). In this study, the typical vertical and horizontal resolution is estimated at approximately 15 to $20 \mathrm{~m}$ and 50 to $600 \mathrm{~m}$ in the incoming sediment and frontal prism, and 40 to $60 \mathrm{~m}$ and 150 to $1,000 \mathrm{~m}$ for the backstop interface, respectively.

\section{Velocity uncertainties in the PSDM analysis}

We estimated the accuracy of the velocity derived from PSDM velocity modeling following Calahorrano et al. 


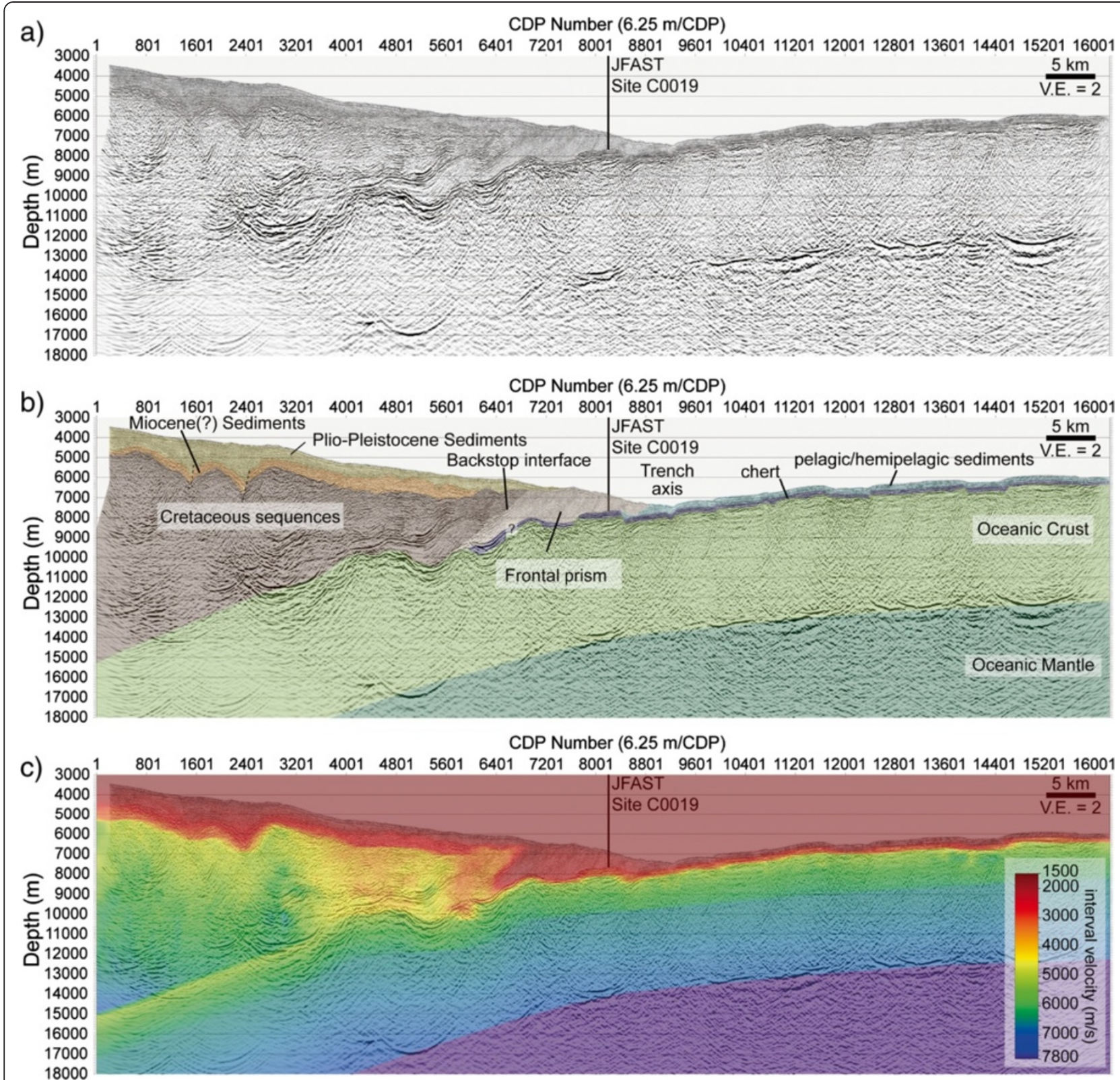

Figure 3 Seismic sections and velocity model of line JFD1. The drill site location is indicated in this section. (a) The PSDM section without interpretation. (b) The PSDM section with interpretation. Interpreted formations are colored over the PSDM section shown in Figure 3a. (c) The PSDM interval velocity model overlain on the PSDM section.

(2008), which evaluates the flatness of the CRP gathers at the target depth. A total of 13 velocity models with $5 \%$ step change (70\% to $130 \%$ of original velocity model) in the velocities were tested. The results show that the velocity in the seaward part of the frontal prism around the JFAST site is determined with approximately $5 \%$ uncertainty, because the velocity models with $10 \%$ perturbation cannot flatten the CRP gathers in this area (Figure $5 \mathrm{a}$ ). The velocity uncertainty is similarly estimated at approximately $5 \%$ in the incoming sediments seaward of the trench and at 5\% to $10 \%$ in the Cretaceous sequences at its seaward edge (around CDP 6600). The uncertainty is larger at greater depth, for example, it increased to approximately $15 \%$ at the landward end of the frontal prism (CDP 6500 to 6700) (Figure 5b). In spite of the larger uncertainty in the landward part of the frontal prism beneath the backstop interface, the velocity inversion across the backstop interface mentioned above is still plausible, because the velocity above the interface (Cretaceous sequence) is $3.2 \pm 0.3 \mathrm{~km} / \mathrm{s}$ and that below (frontal prism) is $2.2 \pm$ $0.3 \mathrm{~km} / \mathrm{s}$. In summary, the velocities shallower than approximately $10 \mathrm{~km}$ depth are generally well determined 


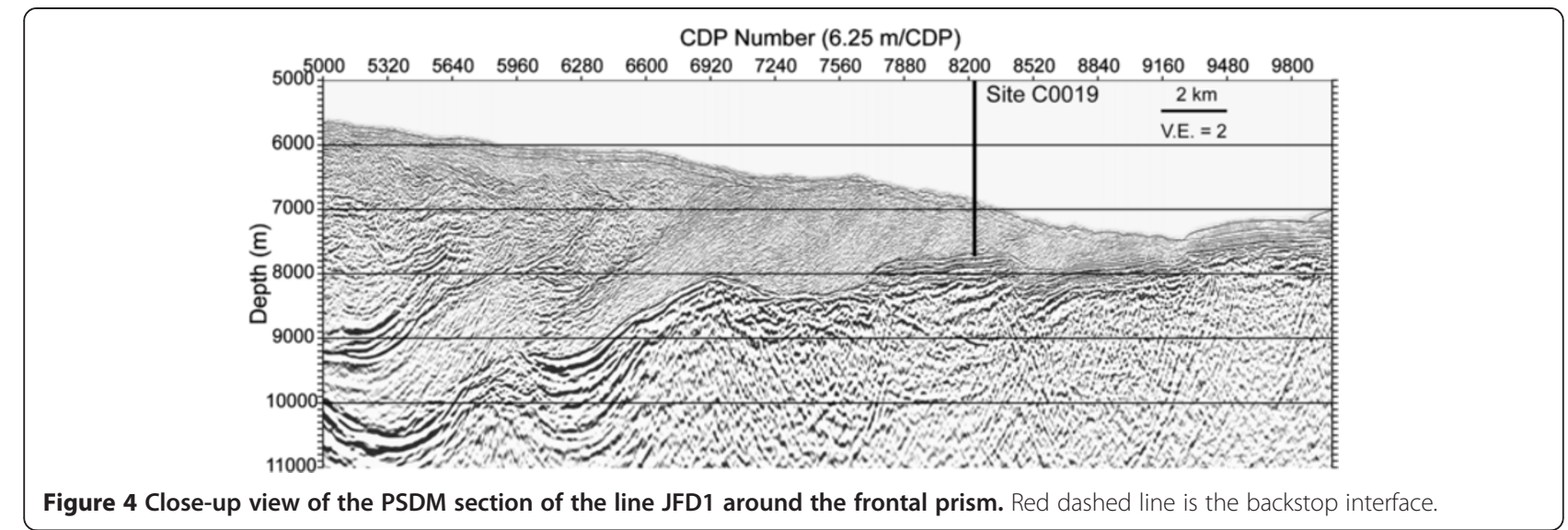

within $5 \%$ to $10 \%$ uncertainty, however, the velocities are poorly controlled so the depth image strongly depends on the reference velocity model in the area deeper than approximately $10 \mathrm{~km}$ below the sea level.

\section{Line JFS12 PoSTM section}

Reflections from the seafloor and the subducting plate stratigraphy are recognized on the seismic profile of line JFS12 (Figure 6), but few internal reflections are observed in the frontal prism. The seafloor reflection is contaminated by artifacts, caused by sideswipes from adjacent slopes, whereas the subducting plate stratigraphy is clearly resolved at a relatively constant two-way travel time of 10,000 to $10,500 \mathrm{~ms}$.

\section{OBS data}

Figure 7a shows vertical component seismograms of air gun shots along the line JFS12 recorded at OBS JF1. The

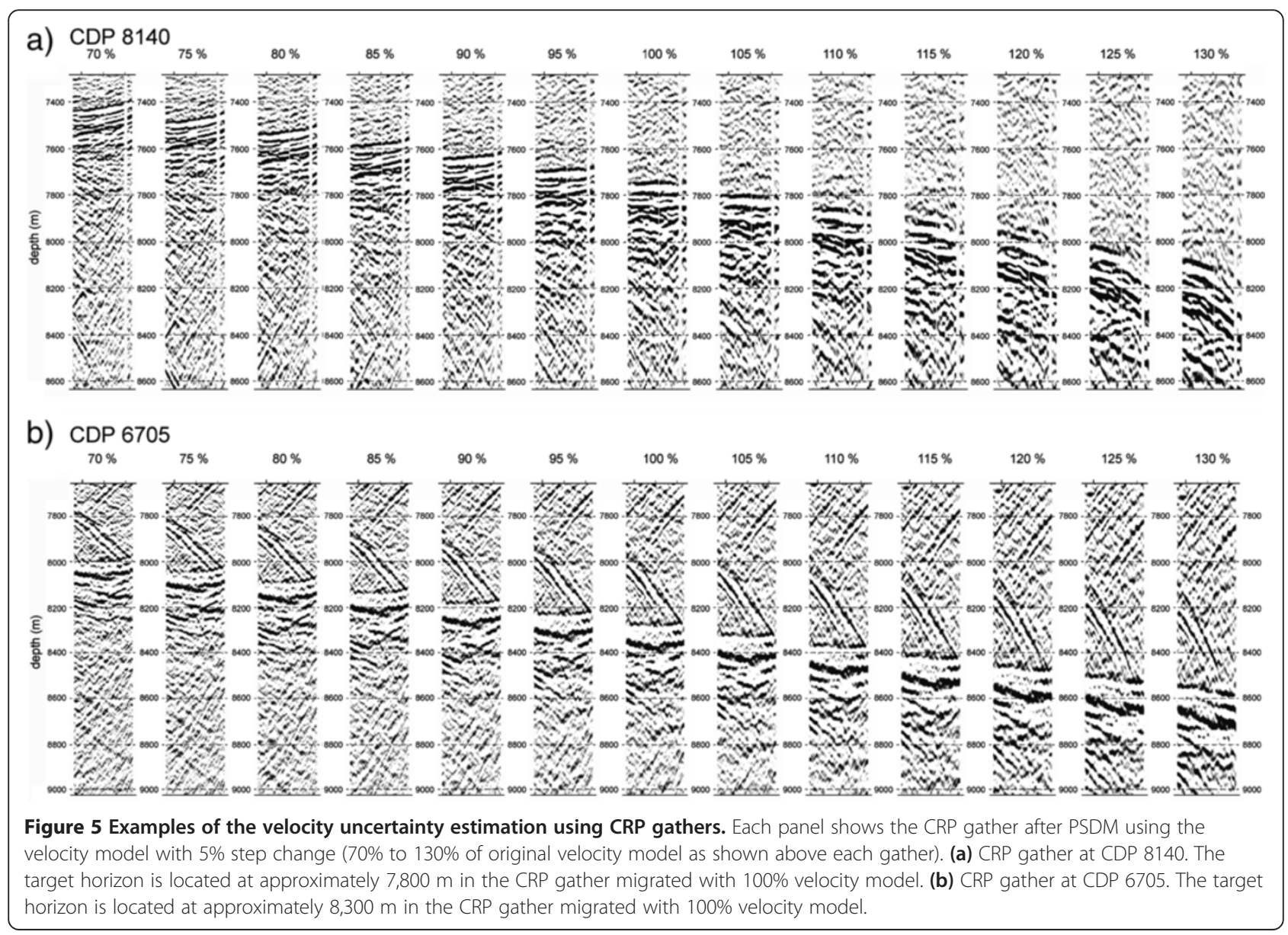




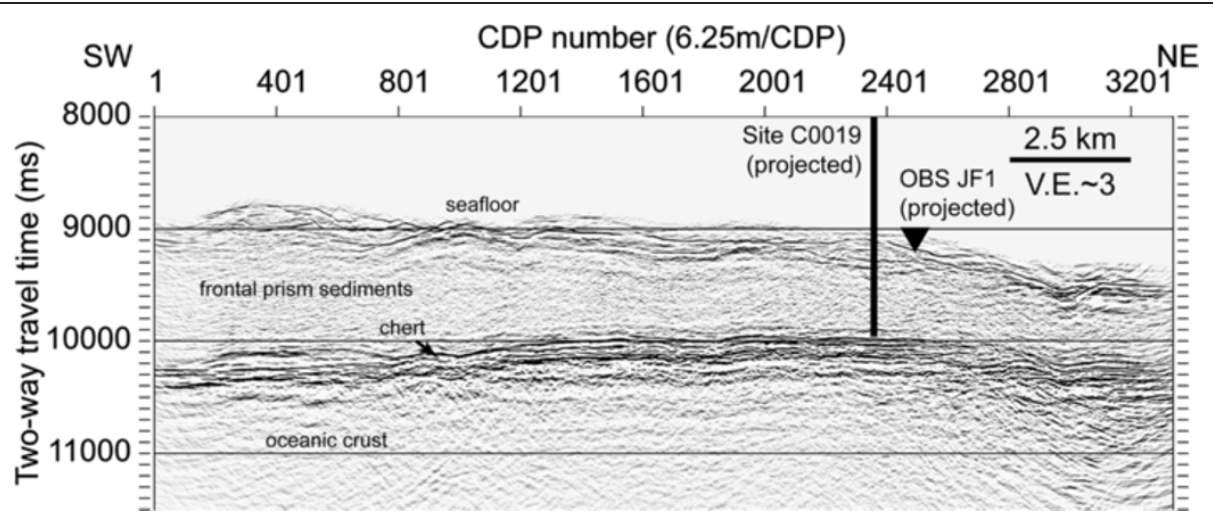

Figure 6 Post-stack time migrated section of the line JFS12. Projected location of the drill site C0019, and the OBS JF1 are indicated on this section.

tau-p converted waveforms using the envelope of the same record, and the deduced $1 \mathrm{D} V \mathrm{p}$ model are shown in the Figures $7 \mathrm{~b}$ and 8 , respectively. The $V \mathrm{p}$ in the sediment layer is between 1.9 and $2.2 \mathrm{~km} / \mathrm{s}$. Figure $9 \mathrm{a}$,b shows the vertical and horizontal component recordings along the line JFS12 recorded at OBS JF1. Travel time was reduced by $6 \mathrm{~km} / \mathrm{s}$. On the vertical component (Figure 9a), a phase with an apparent velocity of approximately $6 \mathrm{~km} / \mathrm{s}$ is clearly detected around $5.5 \mathrm{~s}$ intercept time. Horizontal component record (Figure 9b) also displays the phase with similar apparent velocity but different intercept time at around $7.1 \mathrm{~s}$, which is interpreted as a $\mathrm{P}$ to $\mathrm{S}$ converted wave. PoSTM seismic section of JFS12 (Figure 6) exhibited strong reflections at the top of the chert layer, top of the oceanic crust and the Moho (approximately $12 \mathrm{~s}$ TWT not shown in Figure 6) below the seafloor so we consider that these are the most likely conversion points. This phase can be interpreted as the shear arrival which was converted from P to S around the sediment/ oceanic-crust boundary below the OBS location because it has an apparent velocity similar to the typical $V \mathrm{p}$ value at the top of the oceanic crust (approximately $6 \mathrm{~km} / \mathrm{s}$ ). We can calculate average $V \mathrm{p} / V \mathrm{~s}$ in the sediment beneath the
OBS JF1 using Equation 1, where $d \mathrm{t}$ (time lag), $t_{\mathrm{c}}$ (twoway time of conversion point below the OBS), and $t_{\mathrm{sf}}$ (two-way time of seafloor at OBS location) is $1.6 \pm 0.1$, $10.05 \pm 0.05$, and $9.12 \pm 0.05$, respectively. The uncertainty was evaluated with possible reading errors for each phase which depends on the wavelength of the phase. $V \mathrm{p} / V \mathrm{~s}$ is $4.4+0.7 /-0.5$ assuming the conversion point at top of the oceanic crust. An alternative conversion point could be the top of the chert layer, which is approximately $100 \mathrm{~ms}$ shallower than the top of the oceanic crust beneath the OBS location. If we assume the $\mathrm{P}$ to $\mathrm{S}$ conversion at this boundary, the $V \mathrm{p} / V \mathrm{~s}$ is $4.9+0.8 /-0.7$. Other possible conversion points could be the boundary between oceanic layer two and three and the Moho discontinuity. However, the apparent velocity of this PPS phase is approximately $6 \mathrm{~km} / \mathrm{s}$. This observation suggests that this phase propagated in the oceanic layer two not in layer three, because $V \mathrm{p}$ in oceanic layer three is generally higher than $6.5 \mathrm{~km} /$ $\mathrm{s}$, as can be observed in the survey line $15 \mathrm{~km}$ north of the OBS JF1 (Miura et al. 2005), and the velocity in the upper most mantle is $7.7 \mathrm{~km} / \mathrm{s}$ in the same line (Miura et al. 2005). These velocities are clearly higher than the apparent velocity of this PPS-converted phase. We modeled the
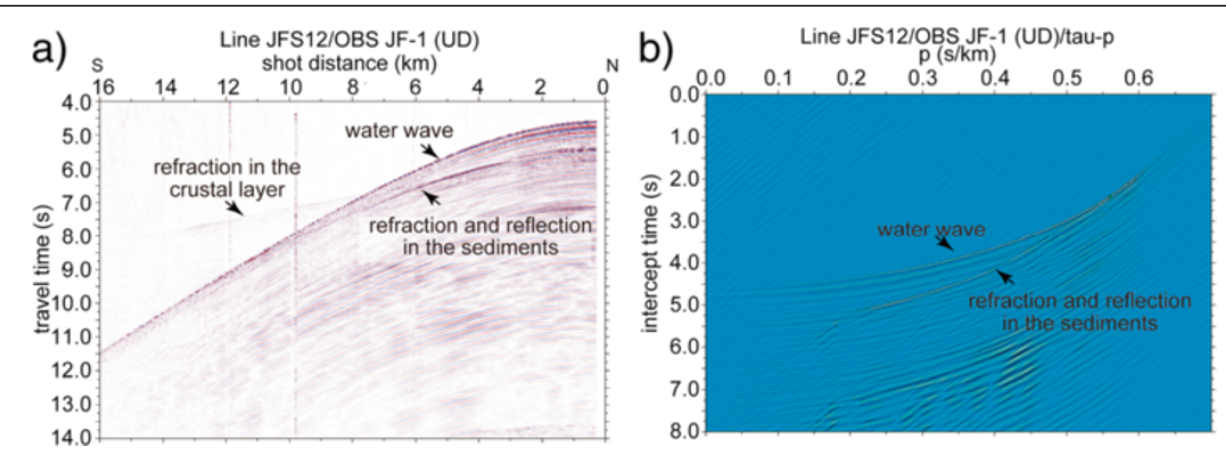

Figure 7 OBS data and its tau-p conversion. (a) The vertical component seismograms at OBS JF1 from shots along the line JFS12. The data were band-pass filtered ( 3 to $12 \mathrm{~Hz}$ ). Some major phases are indicated in this section. (b) The same seismograms as Figure $7 a$ but in tau-p domain. The envelope of the seismograms in Figure 7a was converted into tau-p domain. Major phases are indicated in the section. 


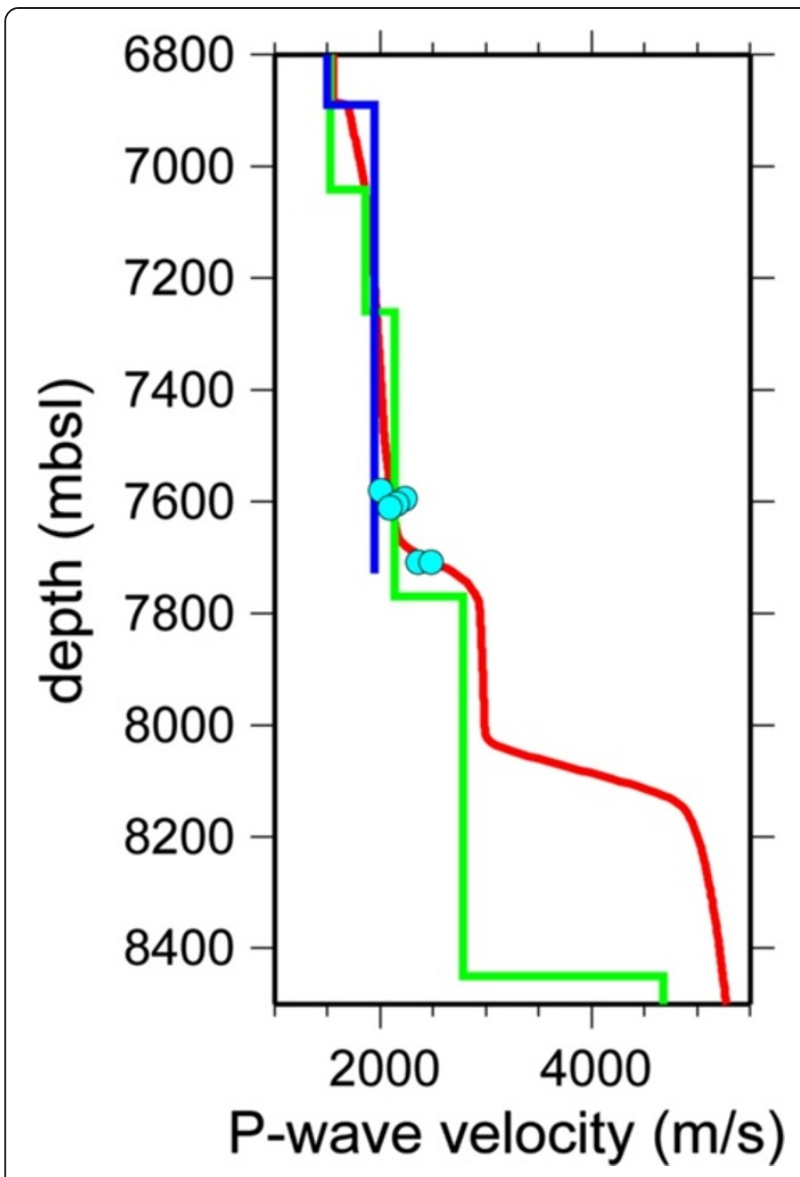

Figure $8 \mathrm{P}$ wave velocity model and measurements around the JFAST site. Red and green lines indicate the velocity models derived from PSDM analysis (CDP 8225) and OBS data analysis (JF1), respectively. Blue line is the averaged interval velocity estimated from the drilling (Expedition 343/343T scientists 2013). Cyan solid circle denotes the $\mathrm{P}$ wave velocity measured from the core samples under the controlled effective pressure. The velocity is estimated from the core experiments (Figure 10) at an in situ effective pressure calculated from the density profile, which was computed from the resistivity logging data (Expedition 343/343T scientists 2013). Note that the OBS location is $1 \mathrm{~km}$ north (see Figure $1 \mathrm{~b}$ ), and the water depth is deeper than the site C0019.

travel-times of the observed phases discussed above with a velocity structure with high $V \mathrm{p} / V \mathrm{~s}$ (4.2 in this case) in the sediment layer (Figure 9c). The observed phases with approximately $6 \mathrm{~km} / \mathrm{s}$ of apparent velocity are well explained as the $\mathrm{P}$ wave traveling through oceanic crust layer 2 , and PPS-converted wave converted at the sediment/crust boundary beneath the OBS location (see also Figure 9a,b). In summary, the average $V \mathrm{p} / V_{\mathrm{s}}$ in the hanging wall sediment should be larger than 3.9 around the JFAST drill site.

\section{Velocities measured from core samples}

Figure 10 shows the velocity changes with effective pressure obtained from the core sample experiments. $V \mathrm{p}$ and $V_{\mathrm{s}}$ approximately ranging from 1.84 to $3.29 \mathrm{~km} / \mathrm{s}$ and from 0.80 to $1.16 \mathrm{~km} / \mathrm{s}$, respectively, over the applied effective pressure range. $V \mathrm{p} / V \mathrm{~s}$ vary between 1.94 and 3.16, corresponding to Poisson's ratio values of 0.32 to $0.44 . V \mathrm{p}, V \mathrm{~s}$, and $V \mathrm{p} / V_{\mathrm{s}}$ values at in situ condition at each coring depth were estimated assuming hydrostatic conditions (Figure 8, Table 2). The lithostatic pressure was estimated from a density curve that was in turn calculated from resistivity logging data, assuming a constant grain density of $2.50 \mathrm{~g} / \mathrm{cm}^{3}$ (Expedition $343 / 343 \mathrm{~T}$ Scientists, 2013). The range of estimated values for in situ $V \mathrm{p}, V_{\mathrm{s}}$, and $V \mathrm{p} / V_{\mathrm{s}}$ are 2.00 to $2.48 \mathrm{~km} / \mathrm{s}, 0.88$ to $1.10 \mathrm{~km} / \mathrm{s}, 2.05$ to 2.48 , respectively.

\section{Discussions}

Seismic structure and velocity in the frontal prism

The frontal prism is located at the seaward edge of the hanging wall, and it is thought to have been horizontally displaced more than $50 \mathrm{~m}$ during the Tohoku earthquake (Fujiwara et al. 2011, Ito et al. 2011). Our PSDM image (Figures 3a and 4) shows a relatively transparent frontal prism, although several landward dipping discontinuous reflections can be distinguished (Figure 4). Some of these reflections extend from the plate boundary to the seafloor and have been previously interpreted as reverse faults (e.g., Tsuji et al. 2013); however, the lack of stratigraphy in the frontal prism makes it difficult to determine the sense of slip. The seismic velocity within the frontal prism is approximately $2.0 \mathrm{~km} / \mathrm{s}$ in average and $2.5 \mathrm{~km} / \mathrm{s}$ at maximum (Figure 3c). The velocity model is comparable with the model in Tsuru et al. (2000) obtained in the Japan Trench approximately $50 \mathrm{~km}$ north of our survey area, but the model in this study has slower velocity in the landward deeper part within the frontal prism. The difference is probably a consequence of the lower velocity gradient value in the velocity model adopted in this study. Park et al. (2010) obtained a detailed seismic image and velocity volume from a 3D reflection seismic data in the Nankai subduction margin off the southwest Japan. Their velocity model shows that the $\mathrm{P}$ wave velocity in the hanging wall accretionary prism is approximately $2.0 \mathrm{~km} / \mathrm{s}$ at the trough axis, but it increases to approximately $3.0 \mathrm{~km} / \mathrm{s}$ at $10 \mathrm{~km}$ landward of the trough axis. They reported the presence of a low velocity zone (LVZ) within the outer wedge of the accretionary prism, 10 to $25 \mathrm{~km}$ landward of the trough axis; however, the velocity is 2.7 to $3.2 \mathrm{~km} / \mathrm{s}$ in the LVZ.

\section{P wave velocities around the site $\mathrm{C} 0019$}

We obtained $V \mathrm{p}$ around the drill site C0019 from two different seismic data analyses: one is from the PSDM analysis using the MCS data and the other is the 1D velocity derived from tau-p/tau-sum analysis on the OBS data (Figure 8). The PSDM velocity has lower velocity 


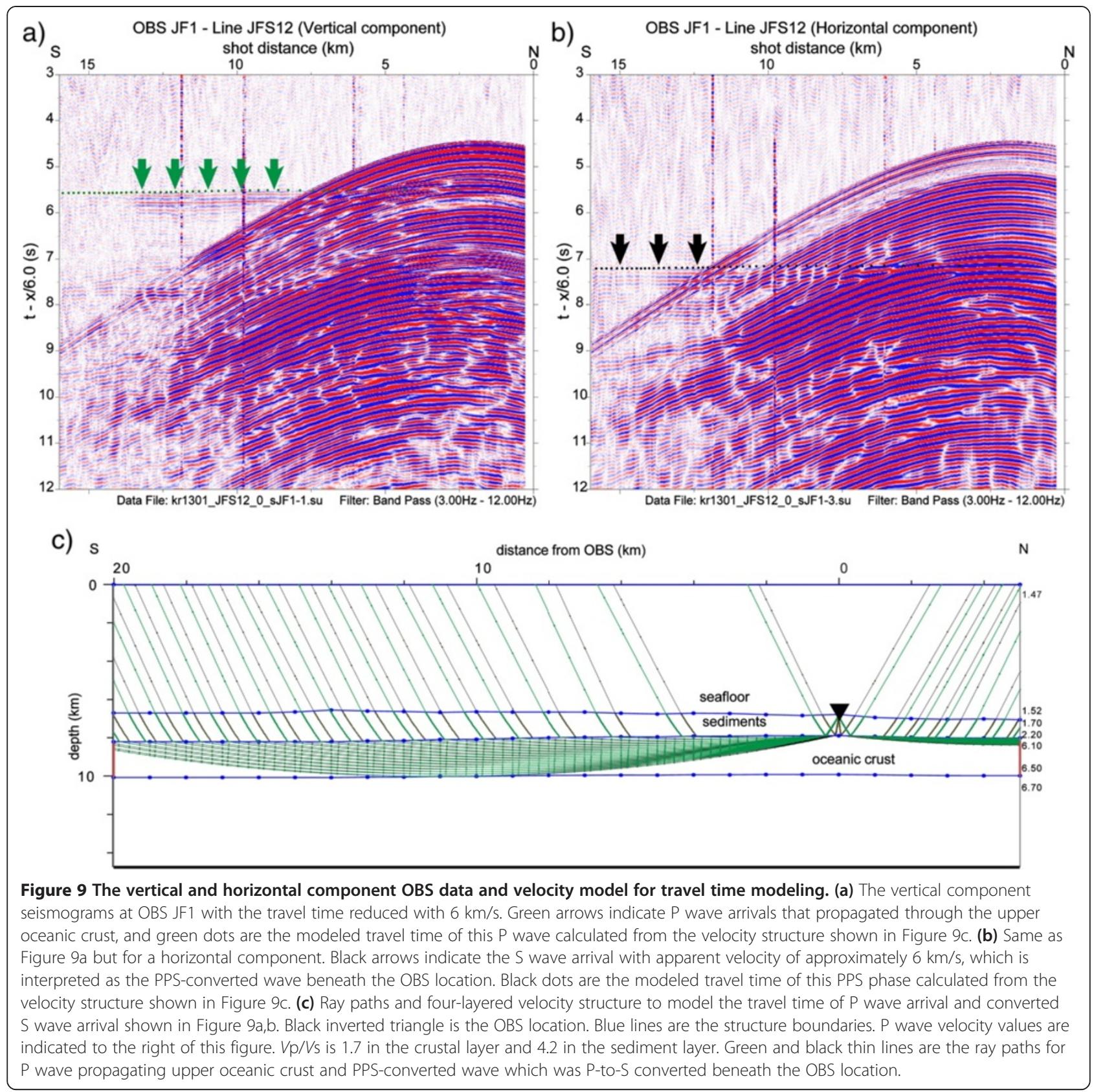

$(1.6 \mathrm{~km} / \mathrm{s})$ at the top of the sediment layer and higher velocity $(2.3 \mathrm{~km} / \mathrm{s})$ at the bottom, with larger gradient than the OBS velocity. Small scale velocity change within the frontal prism is not well resolved from the PSDM analysis due to the lack of internal reflections (Figures 4 and 5). However, the averaged value of the PSDM velocity in the frontal prism formation is approximately $2.0 \mathrm{~km} / \mathrm{s}$, which is comparable with that obtained from the OBS data analysis (Figure 8). The comparison of the seismic data with the drilling results during the Expedition 343 indicated that averaged interval velocity of the interval between the seafloor and the strong reflection near the top of the chert layer is approximately $1.9 \mathrm{~km} / \mathrm{s}$ which is also comparable to the OBS velocity and the averaged PSDM velocity (Figure 8). Estimated in situ $V \mathrm{p}$ values are 2.00 to $2.23 \mathrm{~km} / \mathrm{s}$ for cores $4 \mathrm{R}, 6 \mathrm{R}, 7 \mathrm{R}$, and $8 \mathrm{R}$, which is also consistent with the velocity obtained from the seismic data analysis (Figure 8). For deeper cores, 15R and 16R, in situ $V \mathrm{p}$ is slightly higher, ranging between 2.35 to $2.48 \mathrm{~km} / \mathrm{s}$. These values match with the PSDM velocities (Figure 8); however, the PSDM velocity curve in this depth range $(7,700$ to $7,800 \mathrm{mbsl})$ could be affected by the vertical smoothing during the velocity model building. The higher velocity values measured from 


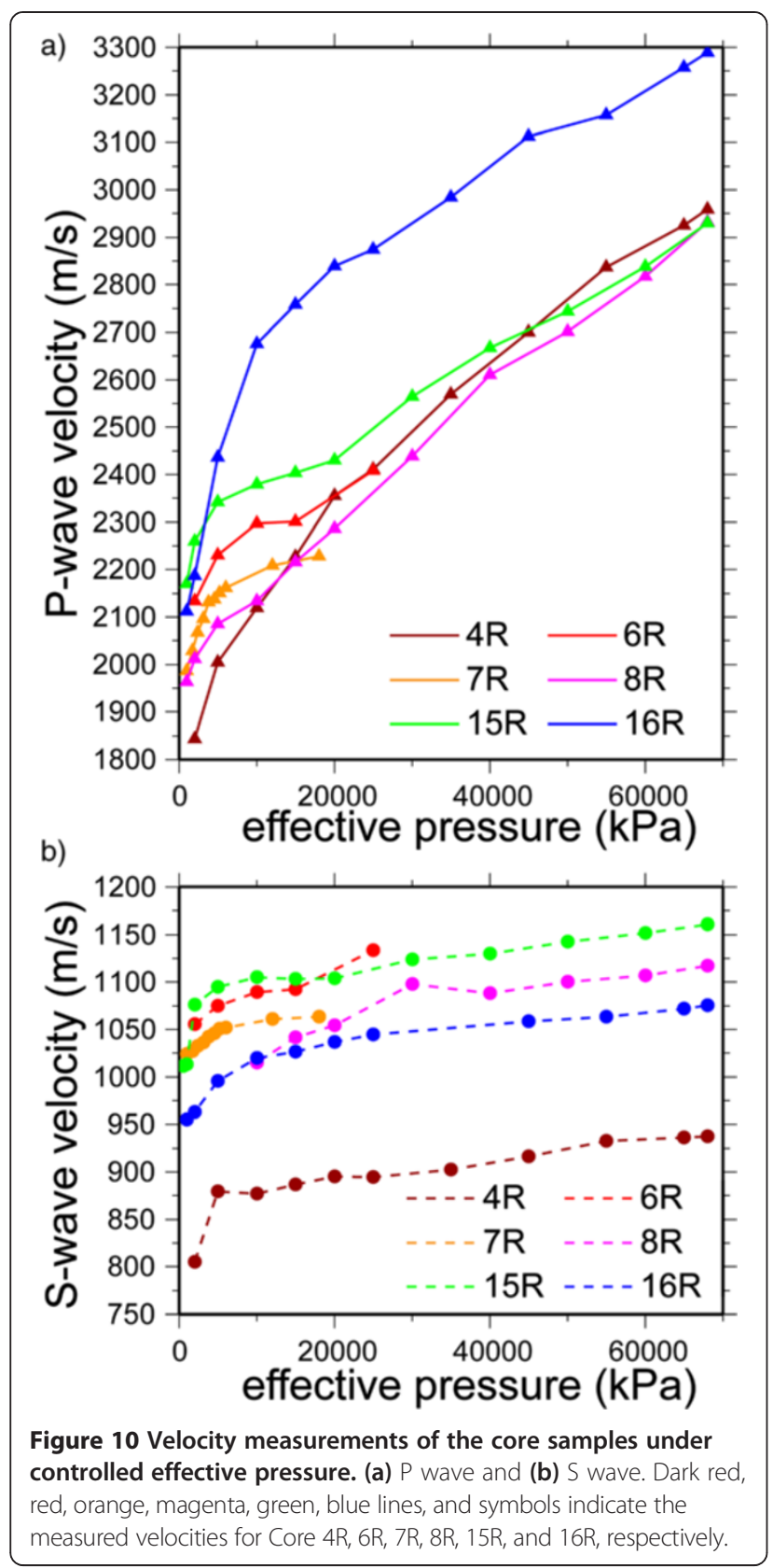

core samples may represent the faster velocity layer at the bottom of the prism, which is below the nominal resolution of the seismic system at this depth level.

\section{High average $\mathrm{Vp} / \mathrm{Vs}$ in the frontal prism}

According to our analysis, the average $V \mathrm{p} / V_{\mathrm{s}}$ ratio in the prism around the site C0019 (or OBS JF1) is $4.4+0.7 /-0.5$ or larger. This is equivalent to a Poisson's ratio $>0.46$ and $V \mathrm{~s}<0.48 \mathrm{~km} / \mathrm{s} . V \mathrm{p}$ and $V \mathrm{~s}$ under the saturated and confined pressure situation (Figure 10, Table 2) give much lower $V \mathrm{p} / V \mathrm{~s} 2$ to 2.5 .
Table 2 In situ velocities, Vp/Vs, and Poisson's ratio estimated from core experiments

\begin{tabular}{lccccc}
\hline Sample & $\begin{array}{c}\text { Depth } \\
(\mathbf{m b s f})\end{array}$ & $\boldsymbol{V p}(\mathbf{k m} / \mathbf{s})$ & $\boldsymbol{V s}(\mathbf{k m} / \mathbf{s})$ & $\boldsymbol{V p} / \boldsymbol{V s}$ & Poisson's ratio \\
\hline Core4R & 690.4 & 2.00 & 0.88 & 2.28 & 0.38 \\
Core6R & 704.3 & 2.23 & 1.08 & 2.08 & 0.35 \\
Core7R & 713.2 & 2.15 & 1.05 & 2.05 & 0.34 \\
Core8R & 720.8 & 2.09 & $\mathrm{~N} / \mathrm{A}$ & $\mathrm{N} / \mathrm{A}$ & $\mathrm{N} / \mathrm{A}$ \\
Core15R & 817.5 & 2.35 & 1.10 & 2.14 & 0.36 \\
Core16R & 818.5 & 2.48 & 1.00 & 2.48 & 0.40 \\
\hline
\end{tabular}

We have compared our results with existing empirical $V \mathrm{p}-V \mathrm{~s}$ relationships. We have used mudrock line for clastic silicate rock (Castagna et al. 1985), which is often used to evaluate the $V \mathrm{p}$ and $V \mathrm{~s}$ in marine sediments. Following the mudrock line $V \mathrm{p}=1.16 V \mathrm{~s}+1.36$, the $V \mathrm{p} /$ $V \mathrm{~s}$ can take significantly large value if the $V \mathrm{p}$ is low. The $V \mathrm{p} / V \mathrm{~s}$ is estimated at 4.08 assuming $V \mathrm{p}=1.9 \mathrm{~km} / \mathrm{s}(5 \%$ reduction from $2.0 \mathrm{~km} / \mathrm{s}$ ), which is located at the lowest possible range from our observation if we consider all uncertainties on the velocity analysis to reduce $V \mathrm{p} / V \mathrm{~s}$. We note that the core measurements were limited to the section deeper than 600 mbsf (Chester et al. 2012), and that the velocity measurements can only be carried on the samples with enough stiffness. It is likely that the shallower frontal prism, which was not sampled during the Expedition 343, and/or the intervals with poor recovery that did not provide adequate samples for measurement, could have larger $V \mathrm{p} / V_{\mathrm{s}}$ increasing the average $V \mathrm{p} / V_{\mathrm{s}}$ value in the hanging wall sediments. Large $V \mathrm{p} / V_{\mathrm{s}}$ values have been reported in the sediments on the incoming plates seaward of the trench and trench fill sediments. The $V \mathrm{p} / V_{\mathrm{s}}$ of the incoming sediments on the Pacific plate in the Kuril Trench was estimated to be approximately 8 from the PPS-converted wave observed by the OBSs (Fujie et al. 2013). Peacock et al. (2010) reported high Poisson's ratio $(>0.45)$ in the trench fill sediments in the Nankai Trough, which corresponds to the $V \mathrm{p} / V \mathrm{~s}$ values larger than 3.3. Similar high $V \mathrm{p} / V \mathrm{~s}$ ratio (approximately 3) was reported for the incoming sediments in the Nankai Trough (Tsuji et al. 2011). On the other hand, Tsuji et al. (2011) reported that the $V \mathrm{p} / V \mathrm{~s}$ value is approximately 2 at the toe of the hanging wall accretionary prism landward of the trough axis in the Nankai Trough, which is approximately half of our observation in the Japan Trench. The Poisson's ratio of sediments is affected by the consolidation, i.e., unconsolidated sediments show high Poisson's ratio (e.g., Prasad 2002). Unconsolidated sediments in the shallowest portion of the prism could contribute to increase the average $V \mathrm{p} / V_{\mathrm{s}}$ and Poisson's ratio. Tsuji et al. (2011) pointed out that the sand-rich turbidite could reduce the $V \mathrm{p} / V \mathrm{~s}$ (and Poisson's ratio). In the Japan Trench, at least 
at the site C0019, sand-rich sediment is not observed in core samples and not suggested by gamma-ray log data. The lack of the sand-rich sediments might be one of the possible reasons to cause the high Poisson's ratio in the Japan Trench prism toe.

\section{Conclusions}

A newly conducted seismic experiment around the JFAST drill site provides a regional-scale depth seismic image and the corresponding velocity models. The obtained PSDM profile exhibits seismically transparent or chaotic frontal prism with several semi-continuous landward dipping reflections beneath the toe of the Japan Trench landward slope. The P wave velocity model derived from the PSDM analysis shows that frontal prism has the low average interval velocity approximately $2.0 \mathrm{~km} / \mathrm{s}$. The backstop interface is clearly imaged, and there is a velocity inversion from the Cretaceous sequences to the underlying frontal prism. The velocity values around the drill site derived from the PSDM analysis are reasonably comparable with the $1 \mathrm{D}$ P wave velocity model estimated from OBS data. The controlled effective pressure core $\mathrm{P}$ wave velocity is also similar to the velocities from the seismic data analysis. The averaged $V \mathrm{p} /$ $V \mathrm{~s}$ calculated from the analysis of seismic data is approximately 4.4 in the hanging wall sediments around the drill site from OBS data, which is considerably larger than that calculated from core measurements. To reconcile these two apparently contradictory observations, it is necessary that the shallower part of the hanging wall sediments, which were not retrieved from core measurements, should have very high $V \mathrm{p} / V \mathrm{~s}$ values. The OBS-derived $V \mathrm{p} / V \mathrm{~s}$ in the hanging wall sediments is also significantly higher than that in the toe of other subduction zones.

\section{Competing interests}

The authors declare that they have no competing interests.

\section{Authors' contributions}

YN participated in the Expedition 343, worked on the drilling-seismic integration, measured velocities on the core onboard, processed and interpreted the seismic data, and wrote the manuscript. SK planned and participated in the KR13-01 cruise as the chief scientist and interpreted the data. BC participated in the Expedition 343 and worked on the seismicdrilling correlation. TJ participated in the Expedition 343 and measured the velocities on core samples except for Core19E-7R. TK participated in the KR13-08 cruise as the chief scientist and recovered the OBS. YY participated in the KR13-01 cruise as the associate chief scientist. YH and MY measured the velocities on the core C0019E-7R. KO developed the Ultra-Deep OBS used at site JF1. GF helped in planning for the KR13-01 cruise and also supported the OBS data analysis and interpretation. All authors participated in the discussion. All authors read and approved the final manuscript.

\section{Acknowledgements}

We thank Dr. Tetsuro Tsuru, Dr. Masataka Kinoshita, and an anonymous reviewer for their valuable comments and suggestions which helped to improve this manuscript. We are grateful to the captains and crews of the research vessel Kairei for their help during the KR13-01 and KR13-08 cruises. We thank Makoto Ito of Nippon Marine Enterprises and his colleagues for their technical assistance during the KR13-01 cruise. We acknowledge Tsutomu Hayashi and Susumu Abe at JGI Inc. for their support in the PSDM analysis. The core sample used in this study was obtained by the Integrated
Ocean Drilling Program. We also thank the captain and crews of the drilling vessel Chikyu during the Expedition 343. The operational and scientific support teams in the Center for Deep Earth Exploration, JAMSTEC are also acknowledged for their support. YN is also supported by a Grant-in-Aid for Scientific Research on Innovative Areas Number 21107002. Some figures were made with Generic Mapping Tools software.

\section{Author details}

${ }^{1}$ Institute for Research on Earth Evolution (IFREE), Japan Agency for Marine-Earth Science and Technology (JAMSTEC), 3173-25 Showa-machi, Kanazawa-ku, Yokohama, Kanagawa 236-0001, Japan. ${ }^{2}$ Research and Development Center for Earthquake and Tsunami (CEAT), Japan Agency for Marine-Earth Science and Technology (JAMSTEC), 3173-25 Showa-machi, Kanazawa-ku, Yokohama, Kanagawa 236-0001, Japan. ${ }^{3}$ National Oceanography Centre, Southampton (NOCS), University of Southampton, Waterfront Campus, European Way, Southampton SO14 3ZH, United Kingdom. ${ }^{4}$ Department of Geoscience, University of Wisconsin-Madison, 1215 West Dayton Street, Madison, WI 53706, USA. ${ }^{5}$ Institute for Research on Earth Evolution (IFREE), Japan Agency for Marine-Earth Science and Technology (JAMSTEC), 2-15 Natsushima-cho, Yokosuka, Kanagawa 237-0061, Japan. ${ }^{6}$ Research and Development Center for Earthquake and Tsunami (CEAT), Japan Agency for Marine-Earth Science and Technology (JAMSTEC), 2-15 Natsushima-cho, Yokosuka, Kanagawa 237-0061, Japan. ${ }^{7}$ Department of Applied Science, Faculty of Science, Kochi University, Akebonocyo 2-5-1, Kochi 780-8520, Japan. ${ }^{8}$ Marine Works Japan Ltd., 3-54-1 Oppamahigashi, Yokosuka, Kanagawa 237-0063, Japan.

Received: 10 March 2014 Accepted: 13 September 2014 Published: 22 September 2014

\section{References}

Calahorrano AB, Sallares V, Collot JY, Sage F, Ranero CR (2008) Nonlinear variations of the physical properties along the southern Ecuador subduction channel: results from depth-migrated seismic data. Earth Planet Sci Lett 267:453-467

Canales LL (1984) Random noise reduction, SEG Technical Program Expanded Abstracts. 525-527, 10.1190/1.1894168

Castagna JP, Batzle ML, Eastwood RL (1985) Relationship between compressionalwave and shear-wave velocities in clastic silicate rocks. Geophysics 50:571-581

Chester FM, Mori JJ, Toczko S, Eguchi N (2012) Expedition 343/343T Scientists. Japan Trench Fast Drilling Project (JFAST), IODP Prel. Rept., 343/343T: 10.2204/iodp.pr.343343T

Chester FM, Rowe C, Ujiie K, Kirkpatrick J, Regalla C, Remitti F, Moore JC, Toy V, Wolfson-Schwehr M, Bose S, Kameda J, Mori JJ, Brodsky EE, Eguchi N, Toczko S The Expedition 343 and 343T Scientists (2013) Structure and composition of the plate-boundary slip zone for the 2011 Tohoku-oki Earthquake. Science 342 (6163):1208-1211, 10.1126/science. 1243719

Claerbout J (1985) Imaging the Earth's interior. Publications, Blackwell Scientific

Diebold JB, Stoffa PL (1981) The traveltime equation, tau-p mapping, and inversion of common midpoint data. Geophysics 46:238-254

Expedition 343/343T Scientists (2013) Site C0019 In: Chester FM, Mori J, Eguchi N, Toczko S (eds) The Expedition 343/343T Scientists, Proc. IODP, 343/343T. Integrated Ocean Drilling Program Management International, Inc, Tokyo, 10.2204/iodp.proc.343343T.103.2013

Fujie G, Kodaira S, Yamashita M, Sato T, Takahashi T, Takahashi N (2013) Systematic changes in the incoming plate structure at the Kuril trench. Geophys Res Lett 40:88-93, doi:10.1029/2012GL054340

Fujiwara T, Kodaira S, No T, Kaiho Y, Takahashi N, Kaneda Y (2011) The 2011 Tohoku-Oki earthquake: displacement reaching the trench axis. Science 334:1240, doi:10.1126/science.1211554

Fulton PM, Brodsky EE, Kano Y, Mori J, Chester F, Ishikawa T, Harris RN, Lin W, Eguchi N, Toczko S (2013) The Expedition 343, 343 T, KR13-08 Scientists (2013) Low coseismic friction on the Tohoku-oki fault determined from temperature measurements. Science 342(6163):1214-1217, doi:10.1126/ science. 1243641

Hashimoto Y, Tobin HJ, Knuth M (2010) Velocity porosity relationships for slope apron and accreted sediments in the Nankai Trough Seismogenic Zone Experiment, Integrated Ocean Drilling Program Expedition 315 Site C0001. Geochem Geophys Geosyst 11:Q0AD05-Q0AD14, 10.1029/2010GC003217

Ide S, Batlay A, Beroza GC (2011) Shallow Dynamic Overshoot and Energetic Deep Rupture in the 2011 Mw 9.0 Tohoku-Oki Earthquake. Science 332:1426-1429, doi:10.1126/science.1207020 
Ito Y, Tsuji T, Osada Y, Kido M, Inazu D, Hayashi Y, Tsushima H, Hino R, Fujimoto H (2011) Frontal wedge deformation near the source region of the 2011 Tohoku-Oki earthquake. Geophys Res Lett 38:『, doi:10.1029/2011GL048355

Kodaira S, No T, Nakamura Y, Fujiwara T, Kaiho Y, Miura S, Takahashi N, Kaneda Y, Taira A (2012) Coseismic fault rupture at the trench axis during the 2011 Tohoku-Oki earthquake. Nat Geosci 5:646-650, doi:10.1038/NGEO1547

Lin W, Conin M, Moore JC, Chester FM, Nakamura Y, Mori JJ, Anderson L, Brodsky EE, Eguchi N (2013) Expedition 343 Scientists (2013) Stress state in the largest displacement area of the 2011 Tohoku-Oki earthquake. Science 339 (6120):687-690, doi:10.1126/science.1229379

Miura S, Takahashi N, Nakanishi A, Tsuru T, Kodaira S, Kaneda Y (2005) Structural characteristics off Miyagi forearc region, the Japan Trench seismogenic zone, deduced from a wide-angle reflection and refraction study. Tectonophysics 407:165-188, doi:10.1016/j.tecto.2005.08.001

Nakamura Y, Kodaira S, Miura S, Regalla C, Takahashi N (2013) High-resolution seismic imaging in the Japan Trench axis area off Miyagi, northeastern Japan. Geophys Res Lett 40:1713-1718, doi:10.1002/grl.50364

Park JO, Fujie G, Wijerathne L, Hori T, Kodaira S, Fukao S, Moore GF, Bangs NL, Kuramoto S, Taira A (2010) A low-velocity zone with weak reflectivity along the Nankai subduction zone. Geology 38:283-286, doi:10.1130/G30205.1

Peacock S, Westbrook GK, Bais G (2010) S-wave velocities and anisotropy in sediments entering the Nankai subduction zone, offshore Japan. Geophys J Int 180:743-758, doi:10.1111/j.1365-246X.2009.04430.x

Prasad M (2002) Acoustic measurements in unconsolidated sands at low effective pressure and overpressure detection. Geophysics 67:405-412

Shinohara M, Hirata N, Takahashi N (1994) High resolution analysis of ocean bottom seismometer data by the tau-p method. Mar Geophys Res 16:181-199

Soubaras R (1995) Prestack random and impulsive noise attenuation by $f-x$ projection filtering. SEG Tech Program Expanded Abstr 1995:711-714, doi:10.1190/1.1887383

Stolt R, Benson A (1986) Seismic migration: theory and practice. Geophysical Press, London

Tobin HJ, Moore JC, Moore GF (1994) Fluid pressure in the frontal thrust of the Oregon accretionary prism: experimental constraints. Geology 22(11):979-982, 10.1130/0091-7613 (1994) 022 <0979: FPITFT> 2.3.CO; 2

Tsuji T, Dvorkin J, Mavko G, Nakata N, Matsuoka T, Nakanishi A, Kodaira S, Nishizawa O (2011) Vp/Ns ratio and shear-wave splitting in the Nankai Trough seismogenic zone: insights into effective stress, pore pressure, and sediment consolidation. Geophysics 76:WA71-WA82, doi:10.1190/1.3560018

Tsuji T, Kawamura K, Kanamatsu T, Kasaya T, Fujikura K, Ito Y, Tsuru T, Kinoshita M (2013) Extension of continental crust by anelastic deformation during the 2011 Tohoku-Oki earthquake: the role of extensional faulting in the generation of a great tsunami. Earth Planet Sci Lett 364:44-58

Tsuru T, Park JO, Takahashi N, Kodaira S, Kido Y, Kaneda Y, Kono Y (2000) Tectonic features of the Japan Trench convergent margin off Sanriku, northeastern Japan, revealed by multichannel seismic reflection data. J Geophys Res 105:16,403-16,413

Tsuru T, Park JO, Miura S, Kodaira S, Kido Y, Hayashi T (2002) Along-arc structural variation of the plate boundary at the Japan Trench margin: implication of interplate coupling. J Geophys Res 107:2357, doi:10.1029/2001JB001664

Ujiie K, Tanaka H, Saito T, Tsutsumi A, Mori JJ, Kameda J, Brodsky EE, Chester FM, Eguchi N, Toczko S (2013) The Expedition 343 and 343 T Scientists (2013) Low coseismic shear stress on the Tohoku-Oki megathrust determined from laboratory experiments. Science 342(6163):1211-1214, doi:10.1126/ science. 1243485

von Huene R, Culotta R (1989) Tectonic erosion at the front of the Japan Trench convergent margin. Tectonophysics 160:75-90

Yilmaz Ö (2001) Seismic data analysis. Society of Exploration Geophysicists, Tulsa, OK

doi:10.1186/1880-5981-66-121

Cite this article as: Nakamura et al: Seismic imaging and velocity structure around the JFAST drill site in the Japan Trench: low $V p$, high $V p / V s$ in the transparent frontal prism. Earth, Planets and Space 2014 66:121.

\section{Submit your manuscript to a SpringerOpen ${ }^{\circ}$ journal and benefit from:}

- Convenient online submission

- Rigorous peer review

- Immediate publication on acceptance

- Open access: articles freely available online

- High visibility within the field

- Retaining the copyright to your article

Submit your next manuscript at $\gg$ springeropen.com 